Hall, B. A., Tarver, M.-G. \& McDonald, J. G. (1959). Fd Technol., Champaign I3, 699.

Harper, R., Bate-Smith, E. C. \& Land, D. G. (1968). Odour Description and Odour Classification. London: J. \& A. Churchill.

Harper, R., Bate-Smith, E. C., Land, D. G. \& Griffiths, N. M. (1968). Perfum. essent. Oil Rec. 59, 22.

Harper, R., Land, D. G., Griffiths, N. M. \& Bate-Smith, E. C. (1968). Br. F. Psychol. 59, 231.

Kramer, A. (1963). Fd Technol., Champaign 17, т596.

Kramer, A. \& Ditman, L. P. (I956). Fd Technol., Champaign Io, I 55.

Mahoney, C. H., Stier, D. L. \& Crosby, E. A. (1957a). Fd Technol., Champaign rx, Suppl. p. 29.

Mahoney, C. H., Stier, D. L. \& Crosby, E. A. (1957b). Fd Technol., Champaign I1, Suppl. 37.

Sjöström, L. B., Cairncross, S. E. \& Caul, J. F. (1957). Fd Technol., Champaign rx, Suppl. p. 20.

von Sydow, E., Andersson, J., Anjou, K., Karlsson, G., Land, D. G. \& Griffiths, N. M. (1970). Lebensm.-Wiss. u. Technol. 3, $\mathrm{I}$.

'Tilgner, D. J. (1962). Fd Technol., Champaign 16, no. 2, 26.

Tilgner, D. J. (1965), Fd Technol., Champaign 19, 25.

Tukey, J. W. (1953). Trans. N.Y. Acad. Sci. Ser II r6, (2) 88.

\title{
On making food attractive
}

\author{
By Roland Harper, Department of Food Science, University of Reading
}

Nutritional programs must recognize the importance of attractiveness of foods. The attractiveness of foods-their flavor, texture, odor and appearance-is nutritionally important since foods are nutritious only when consumed. Consumer acceptance is thus vital to their nutritional value,' (Anonymous, 1969.)

\section{Some historical aspects}

By tradition, much relevant information on making food attractive is contained in books on household management and cookery. We immediately think of Mrs Beeton, but it is possible to find important contributions much earlier. Going no further back than the eighteenth century, The Lady's Companion (Anonymous, I753) with its detailed 'instructions for marketting' and The Art of Cookery Made Plain and Easy (Gasse, 1784) provide two examples. The importance of attractive food is also made explicit in an article on dietetics in the literary edition of Encyclopaedia Britannica (Anonymous, 1878 ) as indicated thus:

'The application of science to the relation of the continuous demands of the body for nutriment aims mainly at three objects, Health, Pleasure and Economy.'

And later: 'A man need not consider that he is wasteful when he spends money upon making his bill of fare palatable and provocative of indulgence even to the extent of moderate superfluity. Pleasure and prudence walk hand in hand.'

Over the years many innovators, both domestic and commercial, could be named. The importance of making food attractive was largely ignored in the initial application of modern knowledge of nutrition and food science. There were many reasons for this, including perhaps an attitude of mind which considered it appropriate to give people what it was considered would do them good rather than what appealed to them. There was a general lack of appreciation among scientific investigators 
at this time of the importance of attractive food and its sensory bases. There were, of course, exceptions. However, it is only during the last decade that the senses of taste and smell have become scientifically respectable and even now the general principles of perception involved are not widely appreciated. These principles have been worked out mainly in the context of vision and hearing, and a comparable body of well-established factual knowledge is just beginning to be assembled. In the last analysis the question of making food attractive is primarily one of human motivation with all its underlying complexities. We are concerned basically with what people are prepared to do rather than what they are capable of doing.

Among the pioneers who emphasized the importance of attractive food was Clark (I943), who examined the schoolchild's taste for vegetables through the medium of the school essay. One of the earliest published reports of consumer attitudes to foods was that of Ferguson (1937). The comprehensive study entitled The Origin of Food Ilabits (Renner, 1944) is another example.

A number of the early nutritional studies were paternalistic in emphasis, attempting to deal with 'the problems of the poor'. The first massive application of the developing knowledge of nutrition and food science in the United Kingdom took place during World War II and was effectively codified in terms of our rationing system. Emphasis was inevitably placed upon what was available rather than what might appeal to the eye or the palate. In fact, things were to get worse before they got better and the years between 1945 and 195 I were the most deprived. 'The general situation has been described in an article entitled Snoek Piquante-The Trials and Tribulations of the British Houseziife, by Susan Cooper (1964). After 25 years we are now just beginning to be able to look back on these experiences with equanimity and even to joke about them as the successful television programme 'Dad's Army' indicates. The author has to admit that at the time it was published the article referred to above was one of the most disturbing documents he has ever read. It may be recalled that in the period after 1945 the average body-weight of the British population actually declined. At the time there was talk of fatigue as 'the English disease'. Under these circumstances it is not surprising that so little emphasis should be placed upon scientific studies related to making food attractive. On the negative side, however, there are documented instances of individuals who refused food because it was unattractive to them even if no alternatives were available.

Rationing in the UK ended in 1955 and with the accompanying gradual rise in the standard of living that sharp boundary between shortage and superfluity of certain food commodities was passed. The possibility of choice rather than mere availability allowed us to become more discriminating. About this time a number of important symposia and other contributions on the sensory evaluation and acceptability of foods began to appear. Perhaps the earliest of these is represented by a series of communications on organoleptic tests in the food industry organized by the Society of Chemical Industry in 1949. Although this was more concerned with quality evaluation rather than with acceptability, the important point was made that much of the early dehydrated vegetables would not have been prepared had systematic taste testing formed a routine part of this development. However, it is essentially the 
middle 1950's which represents the beginning of an explicit interest in the appeal and choice of food to the professional dietician, the nutritionist and the food scientist. In 1954 at the Refresher Course of the British Dietetic Association in Leeds the author was asked to contribute a review entitled Food facts and food fancies as a deliberate diversion from the remaining scientific fare (Harper, 1954). On the same occasion, Miss Hollingsworth discussed the lessons to be learned from the National Food Survey which had been initiated about I940 (Hollingsworth, 1955). In another symposium about this time, Dr Mark Abrams referred orally to some of the progressive changes in attitudes to foods during the present century up to 1955 , which can be summarized in the following list:

$\begin{array}{llc}\begin{array}{c}\text { Phase I } \\ \text { (animal) }\end{array} & \begin{array}{c}\text { Phase II } \\ \text { (chemical) }\end{array} & \begin{array}{c}\text { Phase III } \\ \text { (psychological) }\end{array} \\ \text { Warming } & \text { Protective } & \text { Pleasurable } \\ \text { Fattening } & \text { Nutritious } & \text { Soothing } \\ \text { Filling } & & \text { Eases tension }\end{array}$

What of the present and the immediate future?

We should also note that Professor Yudkin's (1956) inaugural address on his appointment as Professor of nutrition in the University of London dealt with 'Man's choice of food'. This set out many of the factors which influence the choice of food, to which little could be added. 'The event formalized the investigations at Queen Elizabeth College with which we are all familiar.

It would be equally relevant to survey the historical developments in the United States and other countries. There are several threads involved in the development of systematic information about food habits and what makes food attractive. A few early studies in the $1930^{\circ}$ 's were again dirccted towards the problems of feeding the poor. (Note, for example, Gillett \& Rice, 193I; unfortunately this document does not appear to be available in the UK.) A second line of development concerns the beginnings of consumer research on food in the US. The American soldier belongs to a special consumer group and the fact that he was throwing away substantial quantities of good foods in the various theatres of war led to the development of the Food Acceptance Branch of the Quartermaster Food and Container Institute for the Armed Forces in Chicago. Dove (1943, 1947) was responsible for some of the fundamental work which preceded this development as well as for the initial setting up of the Food Acceptance Branch which continued in existence for about 20 years and was under the direction of D. R. Peryam from the early r950's (Peryam, Polemis, Kamen, Eindhoven \& Pilgrim, I960; Kamen, Kroll, Peryam \& Peryam, 1967). Still another development concerns the activities of the (US) National Research Council: Committee on Food Habits (1943, I947). This was set up specially to deal with the problems of postwar rehabilitation with Dr Margaret Mead, the wellknown American anthropologist, as chairman. Some 20 years later she reviewed the earlier work with a view to directing investigations in the same area in the 1960's (Mead, 1964).

The developments of the intervening years will not be considered. However, it is worth noting that a number of the early publications by Dr Rose Marie Pangborn 
of Davis, California, were directly concerned with problems of consumer-acceptability (see, for example, Pangborn, Simone \& Nickerson, 1957). There have been recent changes in terminology in so far as what was traditionally known as 'home economics' is now referred to as 'consumer studies'. Finally, reference has already been made to the recent White House Conference on Food, Nutrition and Health (Anonymous, 1969), which has reopened many long-standing questions with an explicit emphasis upon the importance of attractive food.

\section{An analytical approach}

The idea of an analytical approach to making food attractive is immediately linked in our minds with the extensive micro-analytical studies which have led to a vast amount of information on the chemical constituents of particular foods and how these are affected by processing. However, this information on its own tells us little or nothing about the precise taste or flavours involved and still less about their relative attractiveness. It is well known that many of the most delightful odours of cooked foods contain small quantities of chemicals which on their own would be objectionable. In spite of the practical arts of the flavourist we still lack the basic knowledge of how to predict the perceptual synthesis. It is now fully recognized that a new approach will be necessary to solve these problems. Although contributions to these micro-analytical studies are international, the current position may be summed up by quoting from a critical review on meat flavour; Hornstein \& Crowe (1964) wrote:

The major problem the flavour chemist faces whether in the study of meat flavour or the flavour of some other foodstuff, is how to evaluate the information he already has and continues to acquire. Flavour chemists with the tremendous help of gas chromatography, have concentrated almost all their efforts in trying to solve the analytical aspects of flavour problems. An equally concentrated effort should now be made in trying to understand the meaning of these findings.'

Multidisciplinary studies have to some extent increased since these observations were made but facilities and support essentially for fundamental work involving novel combinations of disciplines are totally inadequate in the UK.

The other aspect of an analytical approach concerns the study of human responses to simple model systems, including mixtures. The characterization of ingredients and simple mixtures has already been discussed at this symposium (Land, 1970). A few observations will be made on evaluating their appeal. It is not possible to discuss the relative merits of many different methods available such as ranking, rating, paired comparisons and so on, but it must be recognized that the method chosen is partly dictated by the task and its surrounding circumstances. Attention will be confined solely to the simple example of the use of a rating scale in which the numbers $\mathrm{I}-7$ or $\mathrm{I}-9$ may be used to represent steps on a scale from the most pleasant to the most unpleasant. A number of studies of this type have been reported in the literature, some dating back to the 1920's. Referring only to relatively recent data, some forty-five odour stimuli were evaluated in this way between 1964 and 1967 
at the Earlham Laboratory, which formed the first stage of the Food Research Institute in Norwich, though these data are yet to be published. These data confirmed that there are certain odours which may be pleasant to some people and unpleasant to others. Some odour stimuli may literally be perceived to be qualitatively different by different persons. These individual differences have again been stressed by Griffiths \& Patterson (1970) in their study of the chemical responsible for boar taint, which appears to show important sex differences.

Reference may also be made to studies of the variation with concentration in the appeal of solutions of the chemicals responsible for the common tastes. The only data available are from small groups of persons, which cannot be regarded as representative samples of the entire population. (See for example, T. Engen, D. McBurney and C. Pfaffmann, unpublished data quoted by Pfaffmann, r96i ; McDermott, I963; Ekman \& Åkesson, r964.) In particular, different substances show different types of response-curves and whereas distinctive subgroups can be found in their reactions (like or dislike) to the different concentration for both sucrose and sodium chloride, group differences are not clearly established with quinine sulphate. In case this information should be considered as trivial it is worth noting that a number of highly successful drinks contain quinine and that at least one of them has an equivalent concentration of quinine sulphate which would generally be unpleasant if present solely in an aqueous solution. This stresses the importance of the effects of successful blending.

Several studies could also be reported in which the importance of the balanced use of sweetening agents in various fruit drinks (and other commodities) has been studied in relation to optimal consumer-responses. The actual data tend to be specific and the general value of such studies lies in their contribution to methods which may be used by others for their own purposes. For example, data relating to the effect on consumer-choice of the balance between sugar and acid in certain fruit juices may be found in US Department of Agriculture, Market Research Reports (Bayton \& Bell, i954; Frye, Hunter \& Van Dress, 1960).

\section{Herbs, spices and condiments}

During the past I $_{5}$ years there has been a renewed and extended interest in herbs and spices, and other special ingredients which might be described as flavour additives, including the so-called flavour potentiators. The traditional importance of herbs and spices is well documented. One might of course go back to the records of antiquity. The importance of herbs and spices in the mediaeval household has been described by Margaret Freeman (1943). It would also be possible to refer to a spate of popular articles one of the most recent of which is entitled Gardens of taste (Roper, I 970). Dried herbs and a variety of manufactured products dependent upon the combined skills of the compounder and the analytical chemist have appeared on the market. One company issued a popular leaflet on The art of flavour magic. This lists some forty-eight herbs and spices and indicates the particular uses of some thirty of these. 
What is involved in compounding and using these and other products is best indicated by summarizing the views of a number of experts expressed through either their publications or their comments. A number of common themes and observations occur in different accounts. Heath (1965) summarized the present position in an article concerned with the problems of spicing meat products. It was confirmed that there are some thirty-six common herbs and spices with which the flavour chemist must be familiar, just as the artist has to be familiar with the colours on his palette.

A seasoning should not normally dominate the flavour complex and, with few exceptions, no one component (herb or spice) should predominate in the seasoning. Such terms as harmony or balance are repeatedly used by different authorities. Without attempting to define them precisely, their meaning is generally selfevident. Recipe compilations, some dating back several centuries, are available. Changing tastes stress the importance of up-to-date recipes for commercial purposes. In practice, those manufacturers without their own experts are recommended to consult the spice houses on the particular problems involved.

It is relevant to reproduce the observations made by Dwyer (I966) in an article on some basic aspects of food science in the field of flavour chemistry. He wrote:

'The fundamental aim of imitation flavour development is to reproduce as closely as possible, the flavour and aroma of natural products. Natural foods and flavouring materials contain aromatic substances that can be reproduced by chemical processes. However, there are certain factors of the food and flavour industries that we must acknowledge. These factors include the paucity of patents, the secrecy of processing and analytical methods, and the definite lack until recent years of scientific publications, in spite of the large amount of work being done. Because of this, flavour development is still primarily creative work. It might be classified as the artistic and practical application of available scientific data. The development of flavours possessing consumer acceptance and flavour fidelity is still contingent upon the imagination, experience and ability of the flavour chemist. He must be able to evaluate by organoleptic tests the usability of newly created synthetic perfumes. He must find the proper places in aroma and flavour complexes for aromatic chemicals and essential oils, as well as the percentages recommended for each complex. He must know the flavour ingredients by their characteristics and properties and their function in the build up of flavour as well as in the finished flavour. He must have the ability to balance mixtures of flavour constituents properly to form one harmonious blend which will present itself as a pleasing flavour entity.'

To quote Heath again, he referred to the following observation by Robert Carrier $\left(\mathrm{I}_{963)}\right.$ in his Great Dishes of the World:

'The correct spice combination is the one that tastes right to you. There are no rules, but be selective. Unless you are following a tested recipe, do not combine too many at one time.'

Here one is also reminded of the effect of mixing indiscriminately too many colours. The total effect will normally be an unattractive mud colour.

In discussing the social and cultural background of food habits in the developing 
countries, de Garine (1970), a French sociologist until recently with FAO, stressed that all traditional societies have their own culinary arts and specific gastronomy. Relevant information may be found in a number of different articles, including those by Aylward (1961, I966), Blair (I966), Jowett (1966) and Niehoff (1967). However, special attention should be drawn to a copiously illustrated pamphlet by Rutishauser ( 1962 ), only recently to hand, which provides detailed information about recipes and cooking methods used by the Baganda in Uganda with matooke(bananas), cassava and yams. This includes information on how to prepare the various 'sauces' which convert these ingredients into attractive dishes.

\section{Recipes and blends}

Both domestically and commercially, making food attractive depends in various ways upon creating a successful recipe or blend. We may note that in a study of over IDo odour stimuli, Moncrieff ( I 966) found that natural odour complexes seemed to be preferred to the odours of single, pure chemicals. Natural fruit flavours may have to be fortified in order to produce an acceptable product. Some natural flavours are considered by consumers to be artificial and the artificial ones natural. According to an editorial in The Flavour Industry (Anonymous, 1970), past activities have been largely confined to matching certain flavours such as vanilla and especially certain types of fruit flavours. The demand for particular flavours is likely to differ from one country to another. For example, blackcurrant flavour does not have the same appeal in other countries as it has in the UK. The demand for compounding non-fruit flavours is relatively new and is expanding. The general attitude of the flavour industry is highly optimistic. A number of commercial successes have been achieved already. These include bread aroma, beef and onion flavour, and bacon flavour. The bread flavour is said to put back into chemically raised bread the natural aroma derived from the yeast-raising process (Downey \& Eiserle, 1966). Opinions still differ about the success of these flavourings and associated products. However, in the UK, some $55 \%$ of all the potato chips sold are now of the flavoured varieties-double what were sold 4 years ago. In the US, the sale of Baco's, a mock meat based upon spun soya protein, recently amounted to 6 million jars per annum (at $5 \mathrm{~s} .6 \mathrm{~d}$. each). This number is equivalent to the world-wide sale of Yorkshire Relish in the I 880 's (Rimmer, I959). Culinary experts or journalists tend to be dissatisfied with the flavours and textures of a number of these new products, although it is generally admitted that the products will sell, just as they have in the US (Beyfus, 1970).

\section{Conclusion}

Perhaps the task of making food attractive is concerned more with meeting individual demands and reactions rather than with the general trends which reflect these individual features only diffusely. The preceding analysis consists of drawing attention to some of the possible variables which may be important. Above all, what is required are more and more firm data, without which we can only speculate 
and argue. No simple and compact summary can be offered which does justice to all the complexities involved. Perhaps some new ways of looking at the age-old question of making food attractive may have been suggested. While stressing the need for multidisciplinary studies involving novel combinations of disciplines this is no new suggestion. As long ago as 1950 , in discussing the role of science in British economy, Meier (1950) pointed to the urgent need for a group of specialists to study the psychology of food prejudices, the chemistry and physiology of flavours, texture analysis and allied activities. These allied activities would now also include nutrition, food science and technology, each of which must give due consideration to the question of making food attractive.

\section{REFERENCES}

Anonymous (1753). The Lady's Companion.

Anonymous (I878). Encylopaedia Britannica, 9th ed. VII, 200, 213. Edinburgh: Adam and Charles Black.

Anonymous (1969). White House Conference on Food, Nutrition and Health. Final Report to the President Panel III-I, p. 3. (Mimeo.)

Anonymous (1970). The Flavour Industry 1, 209.

Aylward, F. (196r). Report to the Government of Ghana on Foods and Nutrition (reprinted 1970). ETAP Rep. no. I 449. Rome: FAO.

Aylward, F. (1966). Chemy Ind. p. I624.

Bayton, J. A. \& Bell, H. P. (1954). Market Res. Rep. U.S. Dep. Agric, no. 76.

Beyfus, D. (1970). The Daily Telegraph Magazine no. 296, p. I6.

Blair, T. L. V. (I966). Fd Technol., Champaign 20, 757.

Carrier, R. ( 1963$)$. Great Dishes of the World. London: Nelson.

Clark, F. E. le G. (1943). The School Child's Taste for Vegetables. Hertford: Stephen Austin Ltd.

Cooper, S. (1964). In The Age of Austerity p. 35. London: Penguin Books.

de Garine, I. (1970). Nutrition Newsletter, FAO 8, 9.

Dove, W. F. (1943). Hum. Biol. 15, 199.

Dove, W. F. (1947). Fd Technol, Champaign, r, 39.

Downey, W. J. \& Eiserle, R. J. (I966). Cereal Sci. Today I , 468.

Dwyer, C. J. (I 666). Technical Quarterly 3, I89.

Ekman, G. \& Akesson, C. (1964). Rep. psychol. Lab. Univ. Stockh. no. 177, p. I.

Ferguson, H. H. (т937). Occup. Psychol. זr, 399.

Freeman, M. B. (1943). Herbs and Spices for the Mediaeval Household. New York: Metropolitan Museum of Art.

Frye, R. E., Hunter, J. S. \& Van Dress, M. G. (I96o). Market Res. Rep. U.S. Dep. Agric. no. 432. Gasse, H. (1784). The Art of Cooking Made Plain and Easy.

Gillett, L. \& Rice, P. (193I). Influence of Education on Food Habits of some New York City Families. New York: New York Association for Improving the Conditions of the Poor.

Griffiths, N. M. \& Patterson, R. L. S. (1970). I. Sci. Fd Agric. 21, 4.

Harper, R. (1954). Nutrition, Lond. 8, 160.

Heath, H. B. (1965). Fd Mf. 40, no. I, p. 52.

Hollingsworth, D. F. (1955). Nutrition, Lond. 9 .

Homstein, I. \& Crowe, P. F. (1964). F. Gas Chromat. 2, 128.

Jowett, D. (I966), Expl Agric, 2, 201.

Kamen, J. M., Kroll, B. J., Peryam, D. R. \& Peryam, D. B. (1967). Analysis of U.S. Army Food Preference Survey (1963). Natick, Mass.: US Army Natick Laboratory.

Land, D. G. (1970). Proc. Nutr. Soc. 29, 309.

McDermott, C. (1 963). Preference curves for quinine sulphate. Unpublished BSc Thesis, Department of Psychology, University of Leeds.

Mead, M. (1964). Publs natn. Res. Coun., Wash. no. I225.

Meier, R. L. (1960). The Manchester School (May), p. Ioi.

Moncrieff, R. W. (I 966$)$. Odour Preferences. London: Leonard Hill Ltd.

National Rescarch Council: Committee on Food Habits (1943). Bull. natn. Res. Coun., Wash. no. ro8. National Research Council: Committee on Food Habits (1947). Bull. natn, Res. Coun., Wash. no. II I. 
Niehoff, A. H. (I967). F. Wash. Acad. Sci. p. zo.

Pangborn, R. M., Simone, M. \& Nicketson, J. A. (1957). Fd Technol., Champaign I I, 679.

Peryam, D. R., Polemis, B. W., Kamen, J. M., Eindhoven, J. \& Pilgrim, F. J. (Ig60). Food Preferences of Men in the U.S. Armed Forces. Chicago: Quartermaster Food and Container Institute for the Armed Forces.

Pfaffmann, C. (196r). Nebraska Symposium on Motivation p. 99 [M. R. Jones, editor]. Lincoln, Nebraska: Nebraska University Press.

Renner, H. D. (1944). The Origin of Food Habits. London: Faber and Faber.

Rimmer, H. G. (I959). The Leeds Fournal 30, 83, 173.

Roper, L. (1970). The Sunday Times Magazine 7 June.

Rutishauser, I. H. E. (1962). The Food of the Baganda. The Uganda Museum Occasional Papers no. 6. Yudkin, J. (1956). Lancet i, 645 .

\section{I Fuly, Second Session}

Chairman : Professor R. L. M. Synge, PhD, FRIC, FRSE, FRS, Nobel Laureate, Agricultural Research Council, Food Research Institute, Norwich

\section{Food selection by ruminants}

By John G. Gordon, Rowett Research Institute, Bucksburn, Aberdeen $A B 2$ gSB

Farm animals can be considered as machines which process raw materials, food and water into products-wool, meat, milk, hides or even tractive power. The basic limiting factors in the process are the potential converting power of the animal and what we are chiefly concerned with in this paper-the potential input and how it is determined. 'This paper discusses some of the factors which determine whether and to what extent a ruminant animal accepts and ingests its food.

The ruminant has no incisor teeth in the upper jaw; instead, these six teeth are replaced by a 'dental pad'. The six chisel-like incisors of the lower jaw bear against the dental pad in the upper jaw and form, together with the lips, a very efficient mechanism for prehension.

Sheep at pasture are specially noted for their ability to select a diet which is, theoretically, distinctly better than is the average herbage available. On grass, the sheep is known to ingest a diet with a considerably greater nitrogen content than is apparent from a general sampling procedure (e.g. Weir \& Torell, 1969). According to Fels, Moir \& Rossiter (1959), this occurs only when the nitrogen concentration in the pasture organic matter is about $3.0 \%$ or less. Selection can vary with time of day and with breed, age, and previous history (Langlands, 1965, 1969). This ability to select has been explained on the basis that the narrow muzzle of the sheep, together with its split upper lip, allows the animal to pick out portions of herbage very precisely. However, we need not jump to conclusions. The domestic cow is usually considered to be a patch selector. It uses its long prehensile tongue to sweep a bunch of fodder into the mouth. This herbage is then clamped between the incisors and the dental pad and is torn off. Apparently this should not allow of 